13.2; 13.4

\title{
Особенности характеристик солнечно-слепых электронно-оптических преобразователей с алмазными фотокатодами
}

\author{
(c) В.А. Беспалов ${ }^{1}$, Э.А. Ильичёв ${ }^{1}$, И.П. Казаков ${ }^{2}$, Г.А. Кирпиленко ${ }^{1}$, А.И. Козлитинн, \\ П.В. Минаков ${ }^{4}$, В.В. Сарайкин ${ }^{3}$, А.В. Клековкин ${ }^{2}$, С.В. Куклев ${ }^{5}$, Г.Н. Петрухин ${ }^{1,6}$, \\ Г.С. Рычков ${ }^{1}$, Д.С. Соколов ${ }^{5}$, Е.Г. Теверовская ${ }^{1}$
}

${ }^{1}$ Национальный исследовательский университет „МИЭТ“, Зеленоград, Москва, Россия

${ }^{2}$ Физический институт им. П.Н. Лебедева РАН, Москва, Россия

${ }^{3}$ Научно-исследовательский институт фризических проблем, Зеленоград, Москва, Россия

${ }^{4}$ Московский государственный университет им. М.В. Ломоносова, Москва, Россия

${ }^{5}$ ООО „МЭЛЗ ФЭУ“, Зеленоград, Москва, Россия

${ }^{6}$ ООО „Си Эн Эл Девайсез“, Зеленоград, Москва, Россия

E-mail: edil44@mail.ru

Поступило в Редакцию 22 июля 2020г.

В окончательной редакции 25 января 2021 r.

Принято к публикации 26 января 2021 г.

\begin{abstract}
Представлены результаты исследований ультрафиолетовых солнечно-слепых электронно-оптических преобразователей с сенсорными слоями фотокатодов из поликристаллических легированных бором алмазных пленок, впервые выращенных на сапфире. Спектральный диапазон чувствительности составляет величину $180-250 \mathrm{~nm}$, пороговая чувствительность без умножителя потока электронов не хуже $\sim 10^{-9} \mathrm{~W} / \mathrm{Hz}^{0.5}$, спектральная чувствительность $12-15 \mathrm{~mA} / \mathrm{W}$.
\end{abstract}

Ключевые слова: алмазный фотокатод, диапазон вакуумного ультрафиолета, электронно-оптический преобразователь, умножитель потока электронов.

DOI: 10.21883/PJTF.2021.09.50897.18480

Разработки сенсоров, чувствительных в ультрафиолетовом диапазоне, чрезвычайно актуальны для широкого класса приборных приложений [1], в то же время не наблюдается существенного прогресса в разработках солнечно-слепых (диапазон вакуумного ультрафиолета (ВУФ), 90-290 nm) сенсоров [2,3]. Проблема частично решается применением нелинейных дорогостоящих полосовых фильтров, однако их характеристики являются температурно-зависимыми. Кроме того, они в значительной степени подавляют полезный сигнал. Ключевой проблемой при разработке ВУФ электронно-оптических преобразователей (ВУФ ЭОП) является разработка солнечно-слепого фотокатода. В России разработками солнечно-слепых ультрафиолетовых фотокатодов для ВУФ ЭОП занимается группа исследователей из Зеленограда [4], а разработки УФ-приемников изображений с использованием традиционных бищелочных фотокатодов и нелинейных полосовых фильтров осуществляются в ЦНИИ „Электрон“ (Санкт-Петербург) [5] и НПО „Катод“ (Новосибирск).

Целью настоящей работы является разработка и исследование солнечно-слепых ультрафиолетовых фотокатодов и ВУФ ЭОП на их основе.

Нами представлены результаты разработок и исследований солнечно-слепых (180-270 nm) ВУФ ЭОП с фотокатодами на основе поликристаллических алмазных пленок, легированных бором. Выбор в качестве сенсорного материала поликристаллических алмазных пленок обусловлен особенностями зонной структуры алмаза, обеспечивающей отсутствие чувствительности к излучениям видимого и ИК-диапазонов и отрицательную энергию сродства для ряда граней алмаза, допускающих реализацию на прозрачных для излучений подложках схемы „на прострел“ в конструкциях ЭОП. Использование триметилбората в качестве легирующей примеси обусловлено хорошей управляемостью процесса легирования и его малой токсичностью. Формирование сенсорной алмазной пленки на сапфировой подложке нами осуществлялось PECVD-методом (мощность СВЧ $1 \mathrm{~kW}$ ) с использованием адгезионного подслоя кремния толщиной $\sim 20-30 \mathrm{~nm}$ и специальным образом приготовленного, нанесенного и фиксированного на адгезионном слое массива из алмазных нанокристаллитов. Расходы водорода и метана составили $\sim 300$ и $\sim 15 \mathrm{~cm}^{3} / \mathrm{min}$ соответственно, давление в газовой смеси $\sim 30$ Torr, a расход раствора триметилбората в изопропиловом спирте $\sim 0.002 \mathrm{~cm}^{3} / \mathrm{min}$. Температура подложки в процессе роста поддерживалась равной $\sim 500-600^{\circ} \mathrm{C}$. Отработка техпроцессов роста и легирования сенсорных пленок сопровождалась контролем качества пленок и уровня легирования посредством изучения спектров комбинационного рассеяния и профиля элементного и фазового состава. Подвижность $\left(\sim 1-3 \mathrm{~cm}^{2} /(\mathrm{V} \cdot \mathrm{s})\right)$ и проводимость в алмазных поликристаллических пленках (при оптимальной концентрации бора в пленке $\sim 10^{19} \mathrm{~cm}^{-3}$ ) контролировались посредством холловских измерений.

На рис. 1 представлены полученные с помощью растрового электронного микроскопа (РЭМ) изображения 


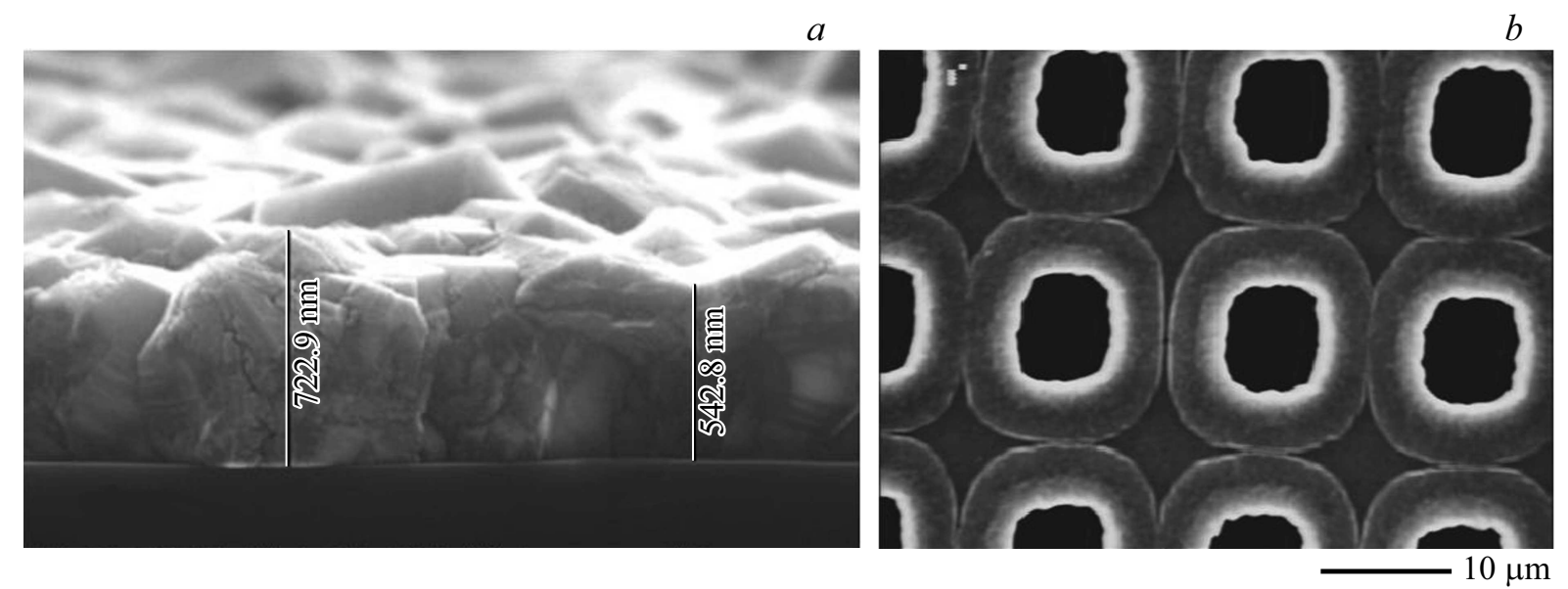

Рис. 1. РЭМ-изображения скола фотокатода на основе поликристаллической алмазной пленки (a) и фрагмента умножителя потока электронов сетчатой алмазной мембранной конструкции $(b)$.
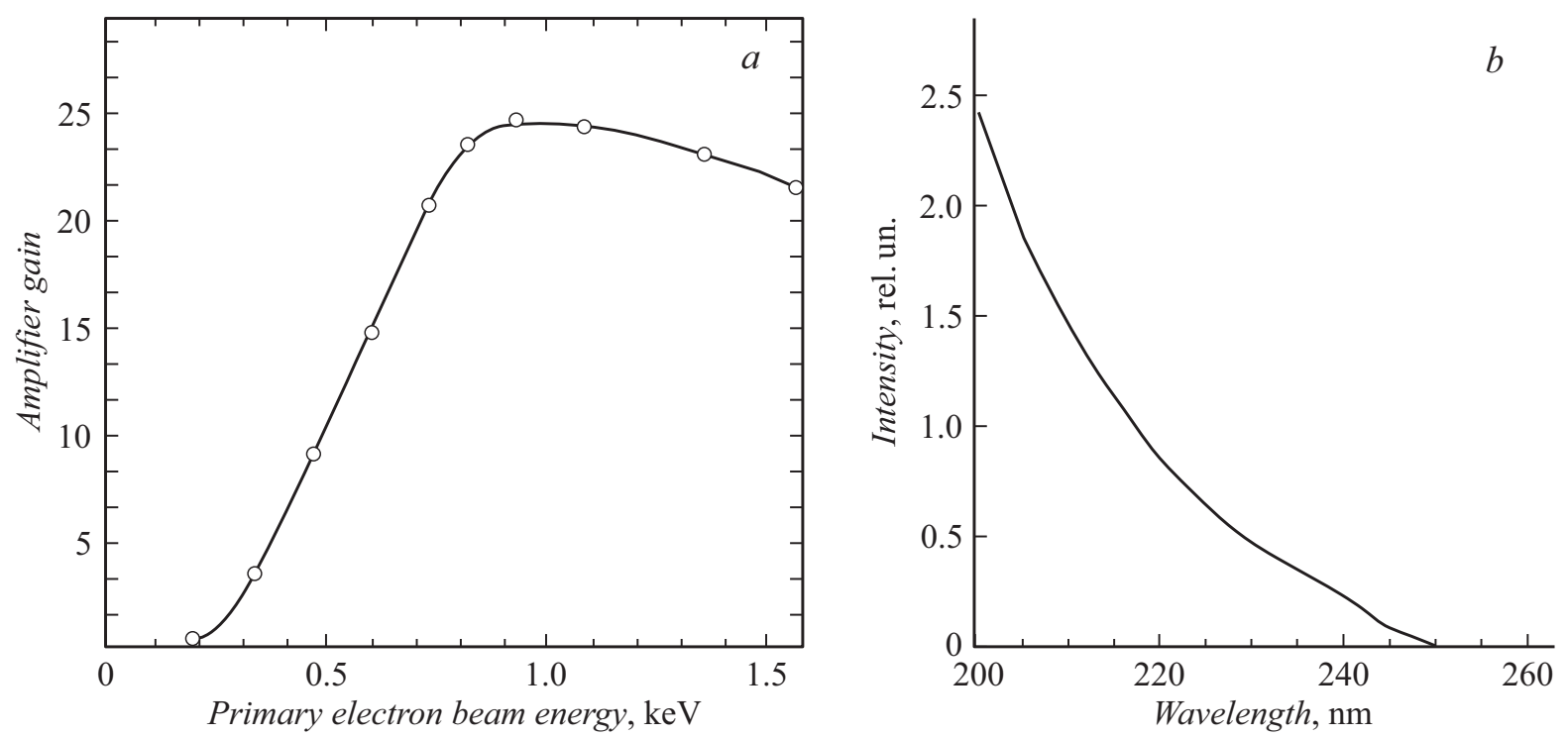

Рис. 2. Типичные умножающие характеристики сетчатых алмазных УПЭ $(a)$ и спектральные характеристики ВУФ ЭОП с алмазным фотокатодом $(b)$.

скола образца типичного фотокатода для ВУФ ЭОП, выращенного на сапфировой подложке PECVD-методом $(a)$, и фрагмента типичного образца алмазного умножителя потока электронов (УПЭ) сетчатой мембранной конструкции $(b)$.

Конструирование УПЭ в виде решетки и выбор конкретных размеров ячеек $(3-5 \mu \mathrm{m})$ и периода $(6-10 \mu \mathrm{m})$ согласованы с величинами диффузионной длины неравновесных носителей в алмазной пленке и нашими технологическими возможностями. Умножающие характеристики сетчатых алмазных УПЭ в схеме „на прострел“ представлены на рис. 2,a. Метод и схема измерений, а также описание измерительного стенда представлены в $[6,7]$.

Спектральные характеристики ВУФ ЭОП, не содержащих в своей структурной схеме УПЭ, представлены на рис. $2, b$. Они получены с использованием оптической схемы, включающей монохроматор МДР 206 с фотодетектирующим обрамлением и широкоаппертурным дейтериевым излучателем ДДС 30. Характеристики спектральной чувствительности ВУФ ЭОП (рис. 2,b) обработаны с учетом особенностей спектральных характеристик фотоприемного устройства монохроматора, излучателя ДДС 30 , а также эталонного $\mathrm{Si} p-n$-фотодиода.

Солнечно-слепой характер чувствительности разработанных ВУФ ЭОП дополнительно подтвержден отсутствием у образцов фотореакции на прямые воздействия мощных источников излучений спектральных диапазонов $840-1080 \mathrm{~nm}$ (галогенная лампа), $633 \mathrm{~nm}$ (Не-Ne-лазер), $540 \mathrm{~nm}$ (суперлюминесцентный диод), 340-380 nm (светодиод, GaN-AlN). 

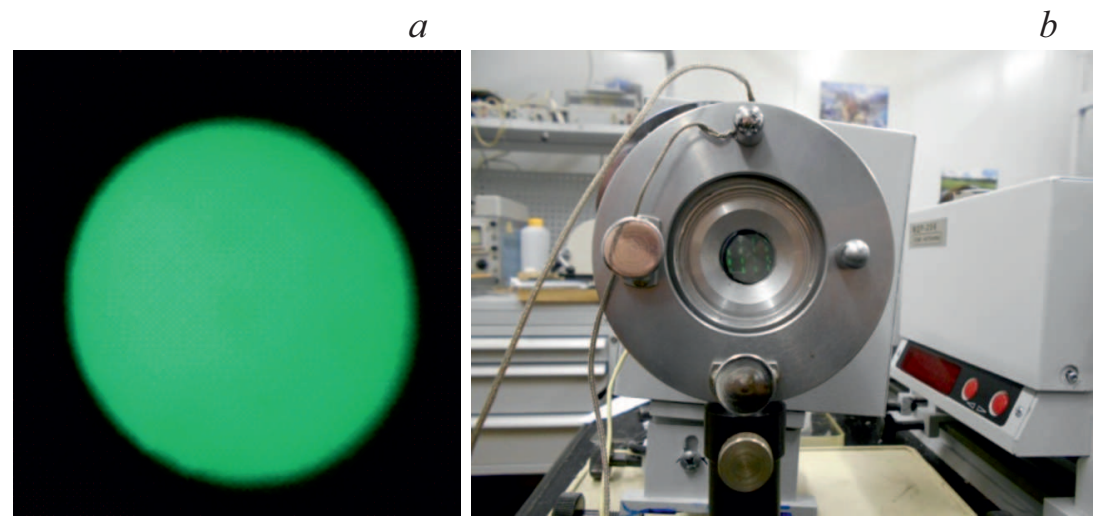

$b$

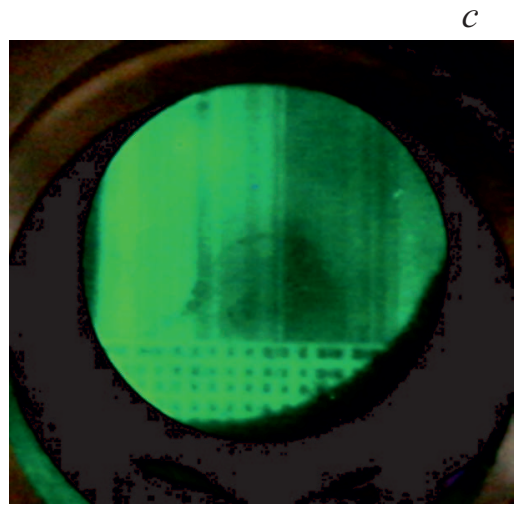

Рис. 3. Картины изображений различных объектов, полученных солнечно-слепым ВУФ ЭОП при разных условиях освещения входного окна излучателем ДДС 30 : случай однородного освещения $(a)$; случай освещения сквозь маску, выполненную в виде решетки $(b)$; случай освещения сквозь кварцевый фотошаблон с топологическим рисунком в виде набора прозрачных квадратов либо мер из набора линий с периодом 6-30 $\mu \mathrm{m}(c)$.

Для исключения ряда артефактов (внутренних утечек по корпусу и автоэмиссионной компоненты) пороговая чувствительность ВУФ ЭОП экспериментально оценивалась снизу посредством регистрации излучения с катодно-люминесцентного экрана со стороны выходного окна ЭОП (со стороны волоконной оптической пластины). Предварительно экспериментально определялась доля интегральной мощности излучения лампы ДДС 30 , вводимой в приемное окно ЭОП, с последующей коррекцией полученных результатов на внешний квантовый выход $\mathrm{Si} p-n$-фотодиода $(\sim 0.30-0.35)$, отношение активных площадей $(\sim 2.5$ раза) входного окна ЭОП и приемного окна $\mathrm{Si} p-n$-фотодиода и на калибровочные данные спектральной зависимости коэффициента преобразования $\mathrm{Si} p-n$-фотодиода в УФ- и видимой областях оптического диапазона (в рабочей области их отношение составило $\sim 0.2$ раза). Затем вычислялась доля мощности излучений для линий видимого диапазона лампы ДДС 30 и определялась мощность, приходящаяся только на ВУФ-область. В результате в качестве оценки для мощности излучения, способного генерировать фотоэлектроны (т.е. для мощности излучения диапазона вакуумного ультрафиолета), получена величина $\sim 50 \mu \mathrm{W}$. Активная мощность $50 \mu \mathrm{W}$, поступающая во входное окно ЭОП, вызывает в цепи эталонного $\mathrm{Si} p-n$-фотодиода, регистрирующего излучение с катодолюминесцентного экрана, фототок величиной в $250 \mathrm{nA}$. Таким образом, с учетом отношения площадей выходного окна ВУФ ЭОП и приемного окна фотодиода (2.5 раза) для его спектральной чувствительности получаем величину $\sim 12-15 \mathrm{~mA} / \mathrm{W}$. Измерения пороговой чувствительности образцов ВУФ ЭОП, включающих УПЭ, и ВУФ ЭОП без УПЭ выполнены с использованием процедуры изменений расстояния от источника ДДС 30 до входного окна ЭОП в диапазоне от $0.2 \mathrm{~cm}$ (coответствующая мощность $50 \mu \mathrm{W}$ ) до $25 \mathrm{~cm}$ (мощность на уровне шума), при которой падающая на входное окно мощность изменялась как квадрат расстояний. В резуль- тате для пороговой мощности ВУФ ЭОП была получена оценка $\sim 3 \cdot 10^{-9} \mathrm{~W}$, что, на наш взгляд, является оценкой снизу. Действительно, измерения пороговых характеристик УФ ЭОП, содержащих УПЭ, нами были выполнены по аналогичной процедуре и дали для пороговой чувствительности величину $\sim 5 \cdot 10^{-11} \mathrm{~W} / \mathrm{Hz}^{0.5}$ при спектральной чувствительности $\sim 65-75 \mathrm{~mA} / \mathrm{W}$ и квантовой эффективности $25-27 \%$. Измерения квантовой эффективности фотокатодов проводились посредством определения отношения потока фотоэлектронов (фототок $\sim 0.6-0.7 \mu \mathrm{A}$ на электроде сбора) к потоку падающих квантов излучений $\left(\sim 5 \cdot 10^{13}\right.$ photon/s) в спектральной области с максимально определенной фоточувствительностью $(\sim 200 \mathrm{~nm})$. Значительная разница в величинах представленных выше пороговой и спектральной чувствительностей конструкторских реализаций ВУФ ЭОП (без УПЭ) и УФ ЭОП, включающего УПЭ, объясняется нами существенным различием (при одинаковых входных мощностях излучений) условий для насыщения каналов безызлучательной рекомбинации в веществе люминофора катодолюминесцентного экрана. Пространственное разрешение УФ ЭОП и ВУФ ЭОП, изученное с использованием эталонных объектов (кварцевое стекло с набором полосок и квадратов), составило $\sim 70$ line $/ \mathrm{mm}$, а поле чувствительности однородно по площади приемного окна (рис. 3).

Таким образом, на основе поликристаллических алмазных пленок, легированных бором, разработана технология получения сенсорно-преобразовательных слоев для солнечно-слепых ВУФ-фотокатодов и умножителей потока электронов. На их основе изготовлены и исследованы экспериментальные образцы солнечно-слепых ВУФ ЭОП.

\section{Финансирование работы}

Работа выполнена с использованием бюджетных средств по госзаданию FSMR-2020-0018 и при под- 
держке Фонда содействия инновациям по проекту № $330 \Gamma \mathrm{P} / 23578$.

\section{Конфликт интересов}

Авторы заявляют, что у них нет конфликта интересов.

\section{Список литературы}

[1] C.L. Joseph, Exp. Astron., 6, 97 (1995).

[2] F. Mendoza, V. Makarov, B.R. Weiner, G. Morel, Appl. Phys. Lett., 107, 201605 (2015). https://doi.org/10.1063/1.4936162

[3] L. Velardi, A. Valentini, G. Cicala, Appl. Phys. Lett., 108, 083503 (2016). http://dx.doi.org/10.1063/1.4942648

[4] В.А. Беспалов, В.М. Глазов, Э.А. Ильичёв, Ю.А. Климов, С.В. Куклев, А.Е. Кулешов, Р.М. Набиев, Г.Н. Петрухин, Б.Г. Потапов, Г.С. Рычков, Д.С. Соколов, В.В. Фандеев, С.С. Якушов, ЖТФ, 85 (4), 74 (2015).

[5] М.Р. Айнбунд, И.С. Васильев, Е.Г. Вилькин, Л.Г. Забелина, Е.Е. Левина, А.В. Пащук, А.С. Петров, Т.А. Русонова, Р.М. Степанов, И.Н. Суриков, Прикладная физика, № 4, 97 (2006).

[6] V.V. Dvorkin, N.N. Dzbanovsky, N.N. Suetin, E.A. Poltoratsky, G.S. Rychkov, E.A. Il'ichev, S.A. Gavrilov, Diamond Relat. Mater., 12, 2208 (2003). DOI: $10.1016 / \mathrm{S} 0925-9635(03) 00320-0$

[7] E.A. Il'ichev, A.E. Kuleshov, E.A. Poltoratskii, G.S. Rychkov, Diamond Relat. Mater., 20, 23 (2011). https://doi.org/10.1016/j.diamond.2010.11.002 